\title{
DINÂMICA DO POTÁSSIO NOS RESÍDUOS VEGETAIS DE PLANTAS DE COBERTURA NO CERRADO(1)
}

\author{
José Luiz Rodrigues Torres ${ }^{(2)} \&$ Marcos Gervasio Pereira ${ }^{(3)}$
}

\begin{abstract}
RESUMO
A produção de biomassa, a manutenção dos resíduos vegetais sobre o solo e sua posterior decomposição são fatores de grande importância no estudo da ciclagem de nutrientes. Este estudo foi desenvolvido na área experimental do CEFET-Uberaba-MG, onde foram avaliados oito tipos de coberturas vegetais: milheto (Pennisetum americanum sin. tiphoydes), braquiária (Brachiaria brizantha), sorgo-forrageiro (Sorghum bicolor L. Moench), guandu (Cajanus cajan (L.) Mill sp.), crotalária (Crotalarea juncea), aveia-preta (Avena strigosa Schreb), pousio e área em preparo convencional de solo (testemunha) em área de Cerrado, na região do Triângulo Mineiro. Avaliaram-se a fitomassa seca (FS), a decomposição dos resíduos em bolsas de decomposição, e a liberação de K. Utilizou-se um modelo matemático para descrever a decomposição dos resíduos e a liberação de $\mathrm{K}$, e calcularam-se a constante de decomposição $(\mathrm{k})$ e o tempo de meia-vida $\left(\mathrm{T}^{1} \frac{1}{2}\right)$. $\mathrm{O}$ milheto, o sorgo e a crotalária foram as coberturas que apresentaram maiores produções de matéria seca. O maior acúmulo de $\mathrm{K}$ ocorreu em gramíneas e a maior liberação de K ocorreu no milheto, aveia, braquiária e crotalária nos primeiros 42 dias após manejo, nos dois períodos avaliados. A braquiária apresentou o menor $T^{1} 1 / 2$ vida e a maior taxa de liberação de $K$.
\end{abstract}

Termos de indexação: decomposição, liberação de $\mathrm{K}$, reciclagem de nutrientes, gramíneas, leguminosas.

\footnotetext{
${ }^{(1)}$ Parte da Tese de Doutorado do primeiro autor, apresentada a Universidade Estadual Paulista - UNESP. Recebido para publicação em agosto de 2007 e aprovado em maio de 2008.

${ }^{(2)}$ Licenciado em Ciências Agrícolas, Professor Classe Especial, Dr. Em Produção Vegetal do Centro Federal de Educação Tecnológica de Uberaba - CEFET/ Uberaba. Av. Edílson Lamartine Mendes, 300. CEP 38045-000, Uberaba (MG). E-mail: jlrtorres@cefetuberaba.edu.br

(3) Engenheiro-Agrônomo, Professor Associado I, Dr. Ciência do Solo do Departamento de Solos, Universidade Federal Rural do Rio de Janeiro - UFRRJ. BR 465, Km 7, CEP 23890-000 Seropédica (RJ). Bolsista do CNPq. E-mail: gervasio@ufrrj.br
} 


\title{
SUMMARY: POTASSIUM DYNAMICS IN CROP RESIDUES OF COVER PLANTS IN CERRADO
}

\begin{abstract}
Crop residue production, plant residue maintenance and their decomposition are important factors in the understanding of nutrient recycling process. To evaluate $K$ accumulation and release a study with eight cover crops types was developed: pearl millet (Pennisetum americanum sin. tiphoydes), brachiaria grass (Brachiaria brizantha), sorghum (Sorghum bicolor L. Moench), pigeonpea (Cajanus cajan (L.) Millsp), sunn hemp (Crotalarea juncea) and black oats (Avena strigosa Schreb), fallow land and conventional culture (control) in the experimental area of CEFET-Uberaba-MG, in a Cerrado area. The dry mass production, crop residue decomposition in litter bags and $K$ release were evaluated. $A$ mathematical model was used to describe residue decomposition and $K$ release, which calculates the decomposition constant $(k)$ and half-time life. Pearl millet, sorghum and the sunn hemp were the cover crops that produced most dry matter while Kaccumulation was highest in the grasses. K release was highest in pearl millet, oats, brachiaria grass and sunn hemp in the first 42 days after handling. Brachiaria grass had the shortest half-time life and the highest $K$ release rate.
\end{abstract}

Index terms: decomposition, K release, nutrient recycling, grasses, leguminosae.

\section{INTRODUÇÃO}

A implantação de sistemas de manejo conservacionistas, que têm como princípio a manutenção de cobertura vegetal e seus resíduos sobre o solo, tem-se destacado como uma das estratégias eficazes para aumentar a sustentabilidade dos sistemas agrícolas nas regiões tropicais e subtropicais (Caires et al., 2006). A eficácia do sistema de semeadura direta está relacionada, dentre outros fatores, com a quantidade e a qualidade de resíduos produzidos pelas plantas de cobertura, a persistência desses resíduos sobre o solo, a velocidade de decomposição e a liberação de nutrientes (Torres, 2003). A maximização da ciclagem de nutrientes, pelo adequado manejo dos resíduos vegetais produzidos num cultivo, é uma opção para aumentar a sustentabilidade dos sistemas agrícolas, otimizando os recursos internos (Chagas et al., 2007). Assim, a decomposição de resíduos em solos aumenta a disponibilidade de nutrientes para as culturas subseqüentes (Reicoscky \& Forcella, 1998), propicia maior liberação de N (Torres et al., 2005), de P (Muzilli, 1981), além de aumentar a disponibilidade de $\mathrm{Ca}$ e $\mathrm{Mg}$, entre outros nutrientes, nas camadas superficiais do solo (Calegari et al., 1992).

A maior parte dos nutrientes das plantas encontrase nos resíduos vegetais, exercendo função estrutural ou como substância de reserva. Parte do estoque de nutrientes torna-se disponível para as plantas em um intervalo curto, contribuindo com a elevação da produtividade das culturas subseqüentes (Souza \& Melo, 2000). O Ké requerido em grandes quantidades pelas culturas, igualando-se às quantidades de $\mathrm{N}$ requeridas, e chegando a ser três ou quatro vezes mais acumulado nos resíduos do que o P (Brady, 1989).

O Ké o cátion mais abundante nos tecidos vegetais, sendo absorvido da solução do solo em grandes quantidades pelas raízes na forma do íon $\mathrm{K}^{+}$. Este nutriente, porém, não faz parte de nenhuma estrutura ou molécula orgânica, sendo encontrado como cátion livre ou adsorvido, o que o torna facilmente trocável das células ou dos tecidos, com alta mobilidade intracelular. As necessidades de K para o ótimo crescimento das plantas situam-se na faixa de 20 $50 \mathrm{~g} \mathrm{~kg}^{-1}$ da massa das partes vegetativas secas da planta, das frutas e dos tubérculos, entretanto as plantas têm a capacidade de absorver quantidade de $\mathrm{K}$ superior à sua necessidade, o que comumente é denominado consumo de luxo de K (Meurer, 2006).

Estudos com diferentes coberturas vegetais vêm sendo realizados em algumas regiões do país e divulgados na literatura, com foco na produção de matéria seca e decomposição dos resíduos culturais, acúmulo e mineralização de nutrientes, relacionando decomposição com fatores climáticos e ação dos microorganismos do solo (Holtz, 1995; Bertol et al., 1998; Oliveira, 2001; Torres et al., 2005; Espíndola et al., 2006; Silva \& Menezes, 2007; Soratto \& Crusciol, 2007).

A taxa de decomposição dos resíduos vegetais é controlada pelas características qualitativas do material vegetal, principalmente pela relação $\mathrm{C} / \mathrm{N}$ e o teor de lignina, pelo manejo que definirá o tamanho dos fragmentos (Bortoluzzi \& Eltz, 2000), que, em conjunto com a ação do clima, principalmente temperatura do ar e precipitação pluvial (Holtz, 1995; Espíndola et al., 2006; Torres et al., 2007) influenciam a atividade dos organismos decompositores (Moore, 1986), podendo acelerar ou reduzir o processo de decomposição.

Durante o crescimento das plantas, parte da biomassa produzida retorna ao solo na forma de galhos, folhas e estruturas reprodutivas, constituindo uma camada de serrapilheira, que, após ser submetida a 
um processo de decomposição, proporciona reciclagem de nutrientes. Costa et al. (2004) avaliaram o aporte deste material em uma área degradada e revegetada com leguminosas arbóreas, e observaram que as concentrações de K nas folhas e nos galhos da capoeira foram superiores em mais de $100 \%$, quando comparadas às quantidades de $\mathrm{K}$ em leguminosas utilizadas na revegetação. Os autores destacam que tal fato se deve à baixa eficiência dos solos da área em reter este nutriente, devido à perda de matéria orgânica e argila em razão do processo erosivo, que contribui para o aumento das perdas de $\mathrm{K}$ por lixiviação, devido a sua alta mobilidade.

Alguns estudos mostram a rápida velocidade de liberação do K, independente da espécie envolvida e da época do corte, e destacam que este fato provavelmente está associado à natureza do nutriente ocorrer na forma iônica nas plantas, não participando de nenhuma das estruturas orgânicas (Taiz \& Zeiger, 1991; Andrade, 1997). Calonego et al. (2005) observaram maiores quantidades de $\mathrm{K}$ lixiviado à medida que o estado de senescência da planta evoluiu após o manejo químico. Sorato \& Crusciol (2007) observaram que a calagem causou aumento dos teores de K na parte aérea das plantas e que, dentre os cátions disponibilizados ao solo após a aplicação, o K é o mais solúvel nos extratos dos resíduos vegetais.

Estudando a decomposição e a liberação de nutrientes acumulados em diferentes coberturas vegetais consorciadas com bananeiras, Espíndola et al. (2006) observaram maior acúmulo de $\mathrm{K}$ nas gramíneas, sendo a decomposição dos resíduos e a liberação do $\mathrm{K}$ mais lentas na estação seca. Considerando o tempo de meia-vida ( $\left.\mathrm{T}^{1} 12\right)$, aproximadamente $50 \%$ dos nutrientes contidos nas leguminosas foram liberados em até 120 dias, e que no período das chuvas este tempo caiu para 60 dias. Ainda com relação ao $\mathrm{K}$, foram observados tempos de meia-vida menores que 13 dias para todas as plantas de cobertura em ambos os períodos avaliados. A percentagem de $\mathrm{K}$ remanescente, avaliada aos 30 dias após o corte, variou de 2 a 15 \% nos resíduos vegetais analisados.
Avaliando a produção de matéria seca, acúmulo e liberação de nutrientes da aveia-preta e do guandu, Borkert et al. (2003) estabeleceram os seguintes intervalos de classe de rendimento de matéria seca (MS): menores que 5,0; entre 5,0 e 7,5; 7,5 e 10; 10,00 e 12,$5 ; 12,5$ e 15,0 ; e maiores que $15,0 \mathrm{t} \mathrm{ha}^{-1}$. Eles observaram que as duas espécies acumularam, em média, 100; 148; 199; 235; 273; e $507 \mathrm{~kg} \mathrm{ha}^{-1}$ de K para a aveia e para o guandu; as médias foram de 20 , 41, 67, 89, 134 e $174 \mathrm{~kg} \mathrm{ha}^{-1}$ de K para esses intervalos, respectivamente, com destaque para a aveia-preta $\mathrm{e}$ para a reciclagem do K. Ambrosano et al. (1997) observaram que mucuna-preta, Crotalária juncea e resíduos da cultura de soja liberaram no solo $102 \mathrm{~kg} \mathrm{ha}^{-1}$ de $\mathrm{K}\left(51 \mathrm{mg} \mathrm{kg}^{-1}\right), 76 \mathrm{~kg} \mathrm{ha}^{-1}$ de $\mathrm{K}$ $\left(38 \mathrm{mg} \mathrm{kg}^{-1}\right)$ e $33 \mathrm{~kg} \mathrm{ha}^{-1}$ de $\mathrm{K}\left(16 \mathrm{mg} \mathrm{kg}^{-1}\right)$, respectivamente, após terem sido manejados.

Diante disso, este estudo teve como objetivo avaliar a produção de matéria seca (MS), a taxa de decomposição e as quantidades acumuladas e liberadas de Kdos resíduos vegetais de plantas de coberturas no Cerrado.

\section{MATERIAL E MÉTODOS}

\section{Caracterização do local}

O estudo foi desenvolvido durante o período de agosto de 2000 a março de 2002, na área experimental do Centro Federal de Educação Tecnológica de Uberaba (CEFET-Uberaba-MG), no município de Uberaba-MG, localizado a $19^{\circ} 39^{\prime} 19^{\prime}$ S e $47^{\circ} 57^{\prime} 27^{\prime \prime} \mathrm{W}$, a aproximadamente $795 \mathrm{~m}$ de altitude. As variações climáticas ocorridas no período de experimentação podem ser observadas na figura 1 . As médias anuais de temperatura máxima e mínima, precipitação média, insolação e umidade relativa do ar são de 29,$0 ; 16,9{ }^{\circ} \mathrm{C} ; 1.639,6 ; 360,4$ e $64,9 \mathrm{~mm}$, num período de 10 anos, respectivamente (Quadro 1) (Abdala, 2005).

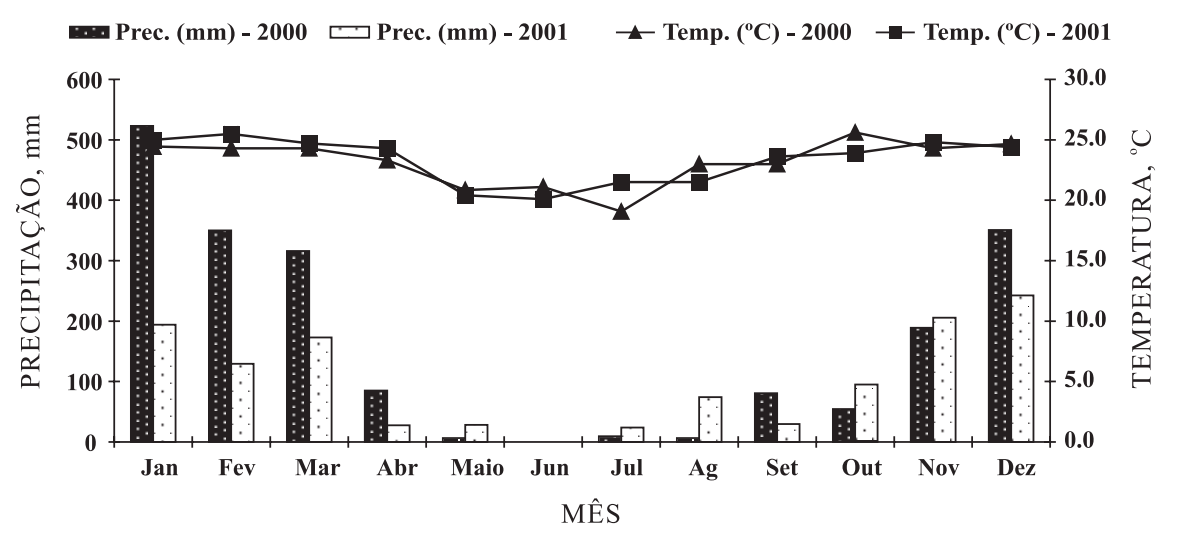

Figura 1. Temperatura e precipitação pluvial média obtida na Estação climatológica de Uberaba INMET/ EPAMIG em 2000 e 2001. 
Quadro 1. Dados climáticos da região de Uberaba do período de 1995 a 2004, extraídos do acervo de dados da Estação climatológica de Uberaba INMET/EPAMIG

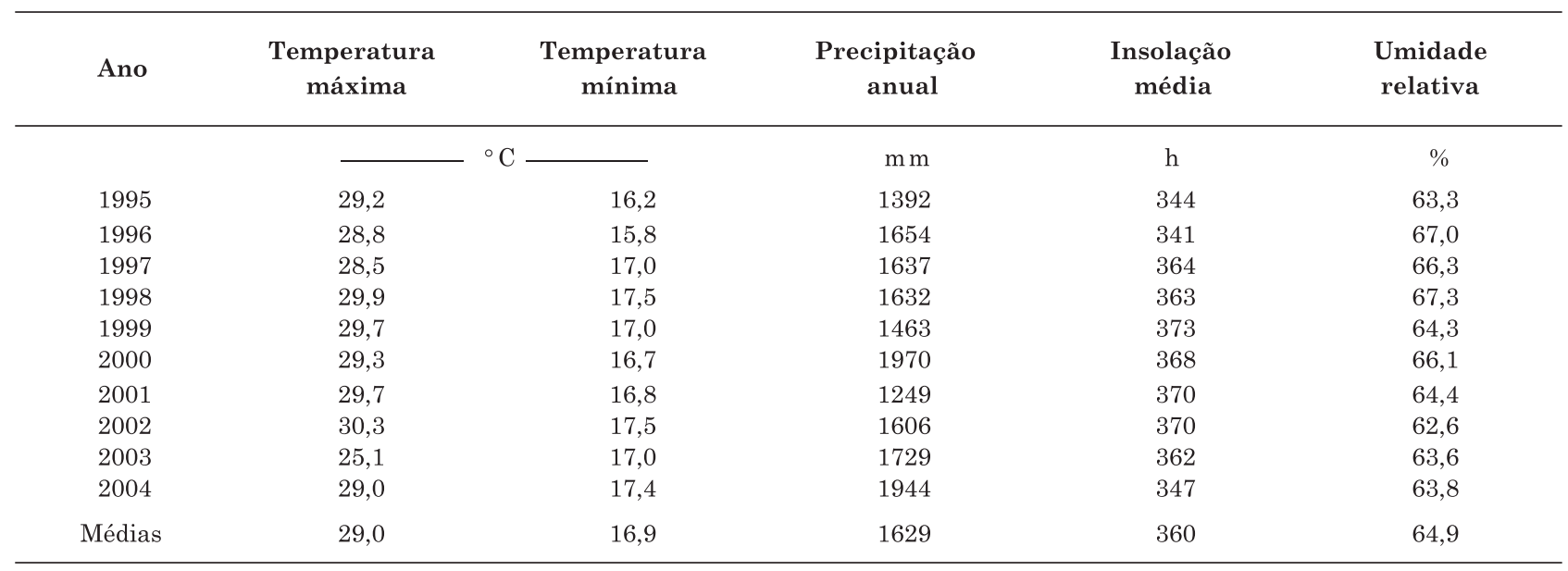

Modificado de Abdala (2005).

O clima é classificado como Aw, tropical quente, segundo a classificação de Köppen, apresentando inverno frio e seco. O solo da área experimental foi classificado como Latossolo Vermelho distrófico (Embrapa, 1999), com as seguintes características na camada arável $(0-20 \mathrm{~cm}) 180 \mathrm{~g} \mathrm{~kg}^{-1}$ de argila, $\mathrm{pH} \mathrm{H} \mathrm{H}_{2} \mathrm{O}$ $(1: 2,5) 6,3 ; 17 \mathrm{mg} \mathrm{dm}^{-3}$ de $\mathrm{P} ; 96 \mathrm{mg} \mathrm{dm}^{-3}$ de $\mathrm{K}$;

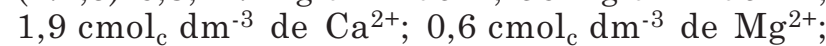
$2,0 \mathrm{cmol}_{\mathrm{c}} \mathrm{dm}^{-3}$ de $\mathrm{H}+\mathrm{Al}$ e $16 \mathrm{~g} \mathrm{~kg}^{-1}$ de matéria orgânica (Embrapa, 1997).

\section{Delineamento experimental e tratamentos}

Na primeira fase do experimento, a semeadura das coberturas vegetais ocorreu em agosto de 2000 e a segunda em abril de 2001, sendo utilizadas as seguintes plantas de cobertura: milheto (Pennisetum americanum sin. tiphoydes), braquiária (Brachiaria brizantha), sorgo-forrageiro (Sorghum bicolor L. Moench), guandu (Cajanus cajan (L.) Mill sp.), crotalária (Crotalarea juncea) e aveia-preta (Avena strigosa Schreb), além de uma área em pousio e uma área testemunha (plantio convencional).O delineamento experimental adotado foi o de blocos casualizados, com quatro repetições, num total de 32 parcelas de $40 \mathrm{~m}^{2}$ (4 x $\left.10 \mathrm{~m}\right)$. Na área de pousio, foi feita a identificação das plantas invasoras, sendo encontradas espécies de diversas famílias, com predomínio de gramíneas.

\section{Avaliação da matéria seca das coberturas}

Para a avaliação da produção de matéria seca (MS) nos dois primeiros ciclos, a dessecação foi feita aos 110 dias após a semeadura (DAS). Fez-se a amostragem em dois pontos ao acaso em cada parcela, com o auxílio de um quadrado metálico de $1,0 \mathrm{~m}^{2}$ de área, que foi lançado aleatoriamente. A seguir, coletouse todo o material contido na área delimitada. O material vegetal foi levado ao laboratório, colocado em estufa de circulação forçada a $65^{\circ} \mathrm{C}$ por $72 \mathrm{~h}$, sendo posteriormente pesado e os resultados expressos em $\mathrm{kg} \mathrm{ha}{ }^{-1}$. Após esta amostragem, as coberturas foram dessecadas aplicando-se $1.440 \mathrm{~g} \mathrm{ha}^{-1}$ de glifosato + $600 \mathrm{~g} \mathrm{ha}^{-1}$ de Paraquat.

\section{Avaliação da taxa de decomposição}

Para a avaliação da taxa de decomposição e liberação de nutrientes, foi empregado o método das bolsas de decomposição (litter bags) conforme descrito por Santos \& Whilford (1981);Schunke (1998) e Espíndola et al. (1998). Em cada bolsa, foram colocados 10 g da parte aérea das plantas de cobertura seca em estufa, a $65^{\circ} \mathrm{C}$, até massa constante, sendo distribuídas vinte sacolas na superfície do solo em cada parcela. Foram realizadas cinco amostragens em cada sacola: a primeira aos 110 DAS, a segunda 42 dias após o manejo (DAM) e as demais em intervalos regulares de 56 dias $(0 ; 42 ; 98 ; 154 ; 210$ DAM). Em cada amostragem coletaram-se quatro sacolas por tratamento. Após a coleta das amostras, o material foi seco em estufa de circulação forçada de ar, a $65^{\circ} \mathrm{C}$ até massa constante e, a seguir, moído.

Para descrever a decomposição dos resíduos vegetais e a liberação de $K$, aplicou-se um modelo matemático exponencial descrito por Thomas \& Asakawa (1993) e utilizado por Rezende et al. (1999) do tipo (1):

$$
\mathrm{X}=\mathrm{X}_{\mathrm{o}} \mathrm{e}^{-\mathrm{kt}}
$$

sendo $\mathrm{X}$ a quantidade de matéria seca remanescente após um período de tempo t, em dias; $\mathrm{X}_{0}$ é a quantidade de matéria seca ou nutriente inicial, e k é a constante de decomposição do resíduo. Aplicando ln e reorganizando a equaão 1 :

$$
\mathrm{k}=\ln \left(\mathrm{X} / \mathrm{X}_{\mathrm{o}}\right) / \mathrm{t}
$$


Considerando que no $\mathrm{T}^{1} \frac{1}{2}, \mathrm{X}=\mathrm{X}_{\mathrm{o}} / 2$ é possível calcular a constante de decomposição $(\mathrm{k})$, e com o valor obtido pode-se calcular o tempo de meia-vida $\left(\mathrm{T}^{1} / 2\right) \mathrm{da}$ matéria seca ou nutriente, pela equação (3):

$$
\mathrm{T}^{1 / 2}=\ln (2) / \mathrm{k}
$$

sendo ln (2) o logaritmo neperiano de dois, que é um valor constante; $\mathrm{k}$ é a constante de decomposição. Os valores obtidos expressam o período de tempo necessário para que metade dos resíduos se decomponha ou para que metade dos nutrientes contidos nesses resíduos seja liberada (Espíndola et al., 2006). Foram elaboradas equações matemáticas que representam a decomposição de matéria seca e a liberação de nutrientes, com auxílio do software SigmaPlot 8.0.

\section{Caracterização química dos resíduos das plantas de cobertura}

A massa seca obtida foi moída e posteriormente submetida à digestão nitricoperclórica. Das soluções obtidas, foram determinados os teores de K (Bataglia et al., 1983) por fotometria de chama (Tedesco et al., 1985). O conteúdo total de $\mathrm{K}$ foi estimado a partir do teor do nutriente de cada amostra, multiplicado pelo peso total de matéria seca estimado em tha ${ }^{-1}$. No material vegetal, foram determindos o $\mathrm{C}$ orgânico pelo método de Walkley e Black modificado, e o N-total pelo método de Kjeldahl (Tedesco et al., 1985). A partir dos dados de $\mathrm{C}$ e $\mathrm{N}$ obtidos, foi calculada a relação $\mathrm{C} / \mathrm{N}$.

Os resultados foram submetidos à análise de variância. Quando este foi significativo, compararamse as médias pelo teste de Tukey $(p<0,05)$. Utilizouse o programa estatístico SAEG, versão 5,0 (Euclides, 1983).

\section{RESULTADOS E DISCUSSÃO}

\section{Avaliação da matéria seca (MS) e relação $\mathrm{C} / \mathrm{N}$ das coberturas}

Com relação à produção de matéria seca, no primeiro ano de estudo (2000/01) observou-se que as gramíneas apresentaram maior rendimento, tendo o milheto se destacado, seguido pelo sorgo e pela braquiária (Quadro 2). Este comportamento pode ser explicado pelas adequadas condições climáticas ocorridas neste período, pois a semeadura coincidiu com o início do período das chuvas. Com relação às leguminosas, a crotalária foi a melhor cobertura, mas produzindo praticamente $1 / 3$ da FS do milheto, ainda assim os valores foram inferiores aos valores encontrados na literatura. O valor obtido pelo milheto foi semelhante ao observado por Chaves (1997), de $10,3 \mathrm{tha}^{-1}$. Para o sorgo, foram menores que os obtidos por Moraes (2001) e por Oliveira (2001), $10,71 \mathrm{t} \mathrm{ha}^{-1}, 15,48 \mathrm{t} \mathrm{ha}^{-1}$, respectivamente, nas mesmas condições de solo e clima.

No segundo ano (2001/02), os valores de FS foram inferiores aos do primeiro ano. Este comportamento pode estar relacionado à época de semeadura das coberturas, que ocorreu no mês de abril, período em que a precipitação foi muito baixa (Figura 1). Associado a este fato, neste ano as coberturas foram submetidas a condições climáticas adversas, baixas taxas de precipitação pluvial $(1.249,1 \mathrm{~mm})$, abaixo do normal na região. Lara Cabezas et al. (2004) verificaram resultados semelhantes, na mesma época de plantio, estudando nabo-forrageiro e milheto como culturas antecessoras do milho no Cerrado mineiro. Neste período agrícola, destacou-se a produção de FS da aveia-preta $\left(3,36 \mathrm{tha}^{-1}\right)$, por estar adaptada às condições de baixas taxas de precipitação e temperatura.

Quadro 2. Produção de matéria seca (MS) e relação C/N das plantas de cobertura, nos anos agrícolas de 2000/ 2001 a 2001/2002

\begin{tabular}{|c|c|c|c|c|}
\hline \multirow[b]{2}{*}{ Cobertura } & \multicolumn{2}{|c|}{$2000 / 01$} & \multicolumn{2}{|c|}{$2001 / 02$} \\
\hline & MS & $\mathrm{C} / \mathrm{N}^{(2)}$ & MS & $\mathrm{C} / \mathrm{N}^{(2)}$ \\
\hline & & 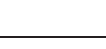 & & \\
\hline Pousio & $2,1 \mathrm{~d}$ & 19,5 & 3,8 a & 25,3 \\
\hline Milheto & $10,3 \mathrm{a}$ & 21,7 & 3,6 a & 25,3 \\
\hline Sorgo & $7,1 \mathrm{~b}$ & 24,3 & $4,0 \mathrm{a}$ & 34,6 \\
\hline Crot alária & $3,9 \mathrm{c}$ & 11,5 & $3,7 \mathrm{a}$ & 18,1 \\
\hline Aveia & $2,4 \mathrm{~d}$ & 30,6 & 3,4 a & 28,3 \\
\hline Guand u & $1,6 \mathrm{~d}$ & 11,3 & $2,7 \mathrm{~b}$ & 16,6 \\
\hline Bra quiária & $6,0 \mathrm{~b}$ & 16,1 & $2,1 \mathrm{c}$ & 19,6 \\
\hline CV (\%) & 20,7 & -- & 10,9 & -- \\
\hline
\end{tabular}

(1) Médias seguidas de mesma letra, na coluna, não diferem entre si a 5\% (Tukey). ${ }^{(2)}$ Não foi feita análise estatística da relação C/ $\mathrm{N}$, porque o teor de $\mathrm{C}$ foi avaliado a partir de uma amostra composta, constituída pelas quatro repetições. 
Quanto à relação C/N nas plantas de cobertura do primeiro ano, observaram-se baixos valores para todas as coberturas, com exceção da aveia-preta. No ano seguinte (2001/02), verificou-se o aumento dos valores desta relação para todas as plantas; a aveia-preta manteve os menores valores, porém próximos ao verificado no ano anterior. Uma possível explicação para o aumento da relação $\mathrm{C} / \mathrm{N}$ no ano agrícola de 2001 pode estar relacionada às condições climáticas que podem ter desfavorecido a absorção de $\mathrm{N}$ pelas gramíneas e a fixação biológica nas leguminosas. Independente do ano agrícola, as leguminosas apresentaram as menores relações $\mathrm{C} / \mathrm{N}$.

\section{Avaliação da taxa de decomposição e tempo de meia-vida $\left(T^{1 / 2}\right)$}

Para a taxa de decomposição, no primeiro ano (2000/01), em todos os tratamentos ocorreu inicialmente uma fase rápida seguida de uma fase mais lenta. Pousio e braquiária foram as coberturas que apresentaram as maiores taxas de decomposição da matéria seca, permanecendo apenas 44,6 e 40,8 \% dos resíduos vegetais, nos primeiros 42 dias após o manejo (DAM), e 12,6 e 11,4\% da matéria seca produzida, respectivamente, aos 210 DAM (Quadro 3).
Fabian et al. (2006), na mesma região, observaram que as taxas de decomposição da braquiária e de pousio foram mais intensas nos primeiros 90 DAM quando comparadas com as da crotalária e do milheto, restando ainda 59 \% da matéria seca aos 120 DAM, porém, como o corte e a dessecação foram mais tardios (190 DAS), a estação mais chuvosa parece ter influenciado nos resultados obtidos.

Milheto, sorgo e guandu foram as plantas que apresentaram menores taxas de decomposição em todo o período avaliado. Embora a crotalária e o guandu apresentem baixa relação C/N (Quadro 2), esta tendência não foi observada, pois aos 210 DAM ainda restavam 36,3 e 38,6 \% dos resíduos vegetais sobre o solo, respectivamente (Quadro 3).

Com a constante de decomposição, pode-se calcular o tempo de meia-vida ( $\left.\mathrm{T}^{1} / 2\right)$ das coberturas de solo, podendo-se observar que metade dos resíduos vegetais provenientes da área de pousio e da área de braquiária havia se decomposto, respectivamente aos 60 dias e aos 56 dias, o que possivelmente possa ser explicado pela baixa relação $\mathrm{C} / \mathrm{N}$ apresentada por estas plantas. Dentre todas as coberturas, as gramíneas foram as que apresentaram maior $\mathrm{T}^{1} \frac{1}{2}$, o que pode ser explicado pela sua maior relação C/N (Quadro 4).

Quadro 3. Percentagem de permanência da matéria seca dos resíduos vegetais das plantas de cobertura, pelo tempo após o manejo, nos anos agrícolas de 2000/2001 e 2001/2002, em Uberaba-MG

\begin{tabular}{|c|c|c|c|c|c|c|c|c|}
\hline \multirow{3}{*}{ Cobertura } & \multicolumn{8}{|c|}{ Dias após o manejo } \\
\hline & \multicolumn{4}{|c|}{$2000 / 2001$} & \multicolumn{4}{|c|}{$2001 / 2002$} \\
\hline & 42 & 98 & 154 & 210 & 42 & 98 & 154 & 210 \\
\hline & \multicolumn{8}{|c|}{ - \% } \\
\hline Pousio & 44,6 & 32,8 & 22,6 & 12,6 & 78,0 & 64,5 & 47,3 & 34,6 \\
\hline Milheto & 64,2 & 57,6 & 43,7 & 32,4 & 63,6 & 52,6 & 39,0 & 30,3 \\
\hline Sorgo & 62,2 & 48,6 & 37,0 & 30,6 & 71,4 & 58,9 & 38,0 & 29,4 \\
\hline Crotalária & 56,2 & 45,4 & 36,3 & 32,2 & 72,5 & 62,4 & 42,8 & 35,0 \\
\hline Aveia & 56,9 & 48,7 & 35,2 & 25,8 & 80,9 & 65,9 & 40,8 & 32,5 \\
\hline Guandu & 67,5 & 51,4 & 36,8 & 30,8 & 74,5 & 51,2 & 34,8 & 22,7 \\
\hline Braquiária & 40,8 & 32,9 & 21,5 & 11,4 & 62,8 & 42,0 & 26,4 & 15,4 \\
\hline
\end{tabular}

Quadro 4. Tempo de meia-vida e $\mathbf{R}^{2}$ do modelo exponencial da, percentagem de permanência da matéria seca dos resíduos vegetais das plantas de cobertura em função do tempo nos anos agrícolas 2000/2001 e 2001/ 2002

\begin{tabular}{|c|c|c|c|c|}
\hline \multirow{3}{*}{ Cobertura } & \multicolumn{4}{|c|}{ Ano agrícola } \\
\hline & \multicolumn{2}{|c|}{$2000 / 2001$} & \multicolumn{2}{|c|}{$2001 / 2002$} \\
\hline & $\mathbf{T}^{1 / 2}$ & $\mathbf{R}^{2}$ & $\mathbf{T}^{1 / 2}$ & $\mathbf{R}^{2}$ \\
\hline & dias & & dias & \\
\hline Pousio & 60 & $0,95^{* *}$ & 143 & $0,98^{*}$ \\
\hline Milheto & 131 & $0,96^{*}$ & 115 & $0,97^{*}$ \\
\hline Sorgo & 117 & $0,96^{*}$ & 118 & $0,99^{*}$ \\
\hline Crotalária & 98 & $0,97^{*}$ & 137 & $0,99^{*}$ \\
\hline Aveia & 110 & $0,96^{*}$ & 130 & $0,98^{*}$ \\
\hline Guandu & 113 & $0,99^{*}$ & 101 & $0,99^{\circ}$ \\
\hline Braquiária & 56 & $0,95^{* *}$ & 78 & $0,99^{\circ}$ \\
\hline
\end{tabular}

${ }^{\circ},{ }^{*} \mathrm{e}^{* *}$ : Significativo a 10,5 e $1 \%$, respectivamente. $\mathrm{T}_{1 / 2}$ : meia-vida. 
No segundo ano agrícola, 2001/02, a taxa de decomposição foi mais lenta para todas as coberturas avaliadas, o que pode ser confirmado pela análise do $\mathrm{T}^{1 / 2}$, que aumentou para todas as coberturas (Quadro 4). Porém, a braquiária continuou sendo a cobertura com a maior taxa de decomposição. A crotalária foi a cobertura com o segundo maior valor $\mathrm{T}^{1} 12$, mesmo apresentando uma das menores relações C/N (Quadro 2). A menor taxa de decomposição verificada no segundo ano pode ser devida aos resíduos vegetais que não se decompuseram durante o primeiro ano e à baixa precipitação pluvial ocorrida $(1.249,1 \mathrm{~mm})$ (Figura1).

Acúmulo e liberação do potássio dos resíduos das plantas de cobertura

As dinâmicas de acúmulo e liberação do K nos resíduos das plantas de cobertura (gramíneas e leguminosas) ocorreram de forma diferenciada. No primeiro ano de estudo (2000/01), observou-se que o maior acúmulo de $\mathrm{K}$ ocorreu naquelas plantas com maior produção de matéria seca (Quadro 2 e 5), porém a liberação do K contido nos resíduos culturais ocorreu de forma diferenciada, pois milheto, aveia e braquiária liberaram 49, 54 e $55 \%$, respectivamente aos 42 DAM, enquanto a crotalária liberou $43 \%$. Porém, para as coberturas guandu, sorgo e pousio, foram verificadas menores taxas de liberação deste nutriente, 25,19 e $10 \%$, respectivamente (Quadro 5). A taxa de acúmulo está relacionada à produção de matéria, porém a liberação parece não estar associada à taxa de decomposição das coberturas (Quadro 3) e ao $\mathrm{T}^{1 / 2}$ (Quadro 4), pois crotalária, pousio e braquiária foram as coberturas que apresentaram maiores taxas de decomposição e menores $\mathrm{T}^{1} 1 / 2$.

No segundo ano (2001/02), a produção de matéria seca e o acúmulo de $\mathrm{K}$ foram inferiores em todas as datas de avaliação, para a maioria das coberturas, sendo exceções a este comportamento as coberturas de pousio, aveia e guandu. A decomposição de todas as coberturas liberou o $\mathrm{K}$ acumulado nos resíduos culturais na faixa de $20 \%$ aos 42 DAM, com exceção do sorgo que ficou na faixa de $10 \%$ (Quadro 6). Além disso, o pousio acumulou $75 \mathrm{~kg} \mathrm{ha}^{-1}$ (Quadro 6) numa matéria seca de $3,8 \mathrm{Mg} \mathrm{ha}^{-1}$, o que pode ser explicado por essas plantas serem de ocorrência espontânea, estando mais adaptadas às condições adversas de clima.

Quadro 5. Potássio acumulado até o dia 110 DAS do manejo e liberação ocorrida nos intervalos avaliados, no ano agrícola de 2000/2001, em Uberaba-MG

\begin{tabular}{|c|c|c|c|c|c|c|}
\hline \multirow[b]{2}{*}{ Cobertura } & \multirow{2}{*}{$\begin{array}{c}\text { K acumulado no } \\
\text { manejo }\end{array}$} & \multicolumn{4}{|c|}{ Dias após o manejo } & \multirow[b]{2}{*}{$\mathrm{CV}$} \\
\hline & & 42 & 98 & 154 & 210 & \\
\hline & \multicolumn{5}{|c|}{$-\mathrm{kg} \mathrm{ha}^{-1}$} & $\%$ \\
\hline Pousio & 23,80 & 21,23 & 15,59 & 10,76 & 6,02 & \multirow{7}{*}{1,6} \\
\hline Milheto & 218,90 & 112,51 & 100,91 & 76,62 & 70,92 & \\
\hline Sorgo & 104,50 & 84,44 & 60,92 & 34,80 & 31,98 & \\
\hline Crotalária & 59,20 & 33,27 & 21,49 & 15,04 & 17,17 & \\
\hline Aveia & 33,40 & 15,23 & 13,03 & 12,06 & 11,76 & \\
\hline Guandu & 31,00 & 23,00 & 15,93 & 13,67 & 12,40 & \\
\hline Braquiária & 214,70 & 96,40 & 84,81 & 60,12 & 34,35 & \\
\hline
\end{tabular}

Quadro 6. Potássio acumulado até o dia 110 DAS do manejo e liberação ocorrida nos intervalos avaliados, no ano agrícola de 2001/2002, em Uberaba-MG

\begin{tabular}{|c|c|c|c|c|c|c|}
\hline \multirow[b]{2}{*}{ Cobertura } & \multirow{2}{*}{$\begin{array}{c}\text { K acumulado no } \\
\text { manejo }\end{array}$} & \multicolumn{4}{|c|}{ Dias após o manejo } & \multirow[b]{2}{*}{$\mathrm{CV}$} \\
\hline & & 42 & 98 & 154 & 210 & \\
\hline & \multicolumn{5}{|c|}{$-\mathrm{kg} \mathrm{ha}^{-1}$} & $\%$ \\
\hline Pousio & 75,80 & 55,26 & 43,96 & 25,09 & 23,65 & \multirow{7}{*}{3,5} \\
\hline Milheto & 56,47 & 44,72 & 26,71 & 17,62 & 10,28 & \\
\hline Sorgo & 43,01 & 38,71 & 17,72 & 11,44 & 8,86 & \\
\hline Crotalária & 39,11 & 32,54 & 19,52 & 10,05 & 10,95 & \\
\hline Aveia & 38,98 & 30,37 & 23,12 & 11,11 & 13,92 & \\
\hline Guandu & 30,59 & 21,63 & 15,66 & 5,32 & 13,21 & \\
\hline Braquiária & 45,79 & 34,71 & 23,08 & 9,66 & 7,74 & \\
\hline
\end{tabular}


Embora no primeiro ano de estudo tenham ocorrido condições climáticas como precipitação $(1.970 \mathrm{~mm})$ e temperatura máxima $\left(29,3^{\circ} \mathrm{C}\right)$, que favoreceriam a decomposição das espécies de coberturas e a liberação do K, com exceção das plantas de cobertura crotalária, aveia e braquiária, esta tendência não foi verificada. Observa-se que, para as demais espécies estudadas, os maiores valores da constante de decomposição foram verificados no ano agrícola de 2001/2002. Dentre as plantas de cobertura, para ambos os anos agrícolas, os maiores valores da constante de mineralização de $\mathrm{K}(\mathrm{k})$ e menores $\mathrm{T}^{1 / 2}$ foram verificados para a braquiária no primeiro ano (2000/01), cujos valores foram de $0,0095 \ln \left(\mathrm{g} \mathrm{g}^{-1}\right) \mathrm{d}^{-1}$ e 73 dias, respectivamente (Quadro 7). Para as áreas de pousio, foram constatados os maiores valores de $\mathrm{T}^{1 / 2}$ e menores valores da constante de mineralização do $\mathrm{K}$.

Quadro 7. Tempo de meia-vida (T 1/2), constante de decomposição do K remanescente contido nos resíduos vegetais das plantas de cobertura nos anos agrícolas 2000/2001 e 2001/2002

\begin{tabular}{|c|c|c|c|c|c|c|}
\hline \multirow{3}{*}{ Cobertura } & \multicolumn{6}{|c|}{ Mineralização de K } \\
\hline & \multicolumn{3}{|c|}{$2000 / 2001$} & \multicolumn{3}{|c|}{$2001 / 2002$} \\
\hline & $\mathrm{T}_{1 / 2}$ & $\mathbf{k}$ & $\mathbf{R}^{2}$ & $\mathrm{~T}^{1 / 2}$ & $\mathbf{k}$ & $\mathbf{R}^{2}$ \\
\hline & dias & $\ln \left(g g^{-1}\right) d^{-1}$ & & dias & $\ln \left(g g^{-1}\right) d^{-1}$ & \\
\hline Pousio & 124 & 0,0056 & $0,96^{*}$ & 114 & 0,0061 & $0,98^{*}$ \\
\hline Milheto & 107 & 0,0065 & $0,84^{*}$ & 90 & 0,0077 & $0,99 *$ \\
\hline Sorgo & 114 & 0,0061 & $0,98^{*}$ & 86 & 0,0081 & $0,94^{*}$ \\
\hline Crotalária & 81 & 0,0085 & $0,91^{*}$ & 96 & 0,0072 & $0,96^{*}$ \\
\hline Aveia & 105 & 0,0066 & $0,73^{*}$ & 115 & 0,0060 & $0,94^{*}$ \\
\hline Guandu & 136 & 0,0051 & $0,95^{*}$ & 103 & 0,0067 & $0,82^{*}$ \\
\hline Braquiária & 73 & 0,0095 & $0,90 *$ & 82 & 0,0084 & $0,98^{*}$ \\
\hline
\end{tabular}

Significância: *: 1 e $\mathrm{T}_{1 / 2}$ : meia-vida.

\section{CONCLUSÕES}

1. Milheto e sorgo (gramíneas) e crotalária (leguminosa) foram as plantas de cobertura de solo que apresentaram as maiores produções de matéria seca.

2. O maior acúmulo de $\mathrm{K}$ ocorreu nas gramíneas (milheto, sorgo e braquiária) no primeiro ano e pousio no segundo ano. A maior liberação de K ocorreu no milheto, na aveia, na braquiária e na crotalária nos primeiros 42 dias após o manejo nos dois períodos avaliados.

3. Dentre as plantas de cobertura estudadas, o milheto foi a que apresentou o conjunto de atributos (acumulação de $\mathrm{K} \mathrm{e} \mathrm{T12/2)} \mathrm{mais} \mathrm{favorável} \mathrm{para} \mathrm{utilização}$ em áreas de Cerrado.

\section{LITERATURA CITADA}

ABDALA, V.L. Zoneamento ambiental da Bacia do Alto Curso do Rio Uberaba-MG como subsídio para a gestão do recurso hídrico superficial. Uberlândia, Universidade Federal de Uberlândia, 2005. 73p. (Tese de Mestrado)

AMBROSANO, E.J., et al. Leguminosas para adubação verde: uso apropriado em rotação de culturas. Campinas, CATI, 1997. 24p.
ANDRADE, A.G. Ciclagem de nutrientes e arquitetura radicular de leguminosas arbóreas de interesse para revegetação de solos degradados e estabilização de encostas. Seropédica. Universidade Federal Rural do Rio de Janeiro, 1997. 182p. (Tese de Doutorado)

BATAGLIA, O.C.; FURLANI, A.M.C.; TEIXEIRA, J.P.F. \& GALLO, J.R. Métodos de análises química de plantas. Campinas, Instituto Agronômico de Campinas, 1983. (Boletim, 78)

BERTOL, I.; CIPRANDI, O.; KURTZ, C. \& BAPTISTA, A.S. Persistência de resíduos culturais de aveia e milho sobre a superfície do solo em semeadura direta. R. Bras. Ci. Solo, 22:705-712, 1998.

BORKERT, C.M.; GAUDÊNCIO, C.A.; PEREIRA, J.E.; PEREIRA, L.R.; OLIVEIRA JUNIOR, A. Nutrientes minerais na biomassa da parte aérea das culturas de cobertura de solo. Pesq. Agropec. Bras., 38:143-153, 2003.

BORTOLUZZI, E.C. \& ELTZ, F.L. Efeito do manejo mecânico da palhada de aveia-preta sobre a cobertura, temperatura, teor de água no solo e emergência da soja em sistema de plantio direto. R. Bras. Ci. Solo, 24:449-457, 2000.

BRADY, N.C. Suprimento e assimilabilidade de fósforo e potássio. In: BRADY, N.C. Natureza e propriedade dos solos. 7.ed. Rio de Janeiro, Freitas Bastos, 1989. p.373413. 
CAIRES, E.F.; GARBUIO, F.J.; ALLEONI, F. \& CAMBRI, M.A. Calagem superficial e cobertura de aveia-preta antecedendo os cultivos de milho e soja em sistema de plantio direto. R. Bras. Ci. Solo, 30:87-98, 2006.

CALEGARI, A.; FERRO, M.; GRZESIUK, F. \& JACINTO JUNIOR, L. Plantio direto e rotação de culturas: experiência em Latossolo roxo/1985-1992. Curitiba, COCAMAR/ZENECA Agrícola, 1992. 64p.

CALONEGO, J.C.; FOLONI, J.S.S. \& ROSOLEM, C.A. Lixiviação de potássio da palha de plantas de cobertura em diferentes estádios de senescência após a dessecação química. R. Bras. Ci. Solo, 29:99-108, 2005.

CHAGAS, E.; ARAÚJO, A.P.; TEIXEIRA, M.G. \& GUERRA, J.M.G. Decomposição e liberação de nitrogênio, fósforo e potássio de resíduos da cultura do feijoeiro. R. Bras. Ci. Solo, 31:723-729, 2007.

CHAVES, C.A.S. Produção e valor nutritivo das silagens de capim Sudão (Shorgum sudanense (Piper) Stapf), milheto (pennisetum americanum (L.) Leeke), teosinto (Euchlaena mexicana Scharad) e milho (Zea mays L.). Lavras, Universidade Federal de Lavras, 1997. 56p. (Tese de Mestrado)

COSTA, G.S.; FRANCO, A.A.; DAMASCENO, R.N. \& FARIA, S.M. Aporte de nutrientes pela serrapilheira em uma área degradada e revegetada com leguminosas arbóreas. R. Bras. Ci. Solo, 28:919-927, 2004.

EMPRESA BRASILEIRA DE PESQUISA AGROPECUÁRIA EMBRAPA. Centro Nacional de Pesquisa de Solos. Sistema brasileiro de classificação de solos. Brasília, Produção de Informação, 1999. 412p.

ESPINDOLA, J.A.A.; GUERRA, J.G.M.; ALMEIDA, D.L.; TEIXEIRA, M.G. \& URQUIAGA, S. Decomposição e liberação de nutrientes acumulados em leguminosas herbáceas perenes consorciadas com bananeiras. R. Bras. Ci. Solo, 30:321-328, 2006.

EUCLIDES, R.F. Manual de utilização do programa SAEG (Sistema para Análises Estatísticas e Genéticas). Viçosa, MG, Universidade Federal de Viçosa, 1983. 59p.

FABIAN, A.J.; CORÁ, A.J. \& TORRES, J.L.R. Plantas de cobertura: produção de fitomassa, decomposição e porcentagem de cobertura do solo. In: REUNIÃO BRASILEIRA DE MANEJO E CONSERVAÇÃO DO SOLO E ÁGUA, 16., Aracaju, 2006. Anais... Aracaju, SBCS/ Embrapa Tabuleiros Costeiros/UFS, 2006. CD-ROM.

HOLTZ, G.P. Dinâmica da decomposição da palhada e a distribuição do carbono, nitrogênio e fósforo numa rotação de culturas sob plantio direto na região de Carambeí/PR. Curitiba, Universidade Federal do Paraná, 1995. 129p. (Tese de Mestrado)

LARA CABEZAS, W.A.R. Influencia da cultura antecessora e da adubação nitrogenada na produtividade de milho em sistema de plantio direto e solo preparado. Ci. Rural, 34:1005-1013, 2004

MEURER, E.J. Potássio. In: FERNANDES, M.S. Nutrição mineral de plantas. Viçosa, MG, Universidade Federal de Viçosa, 2006. p.281-298.
MOORE, A.M. Temperature and moisture dependence of decomposition rates of hard-wood and coniferous leaf litter. Soil Biol. Chem., 18:427-435, 1986.

MORAES, R.N.S. Decomposição das palhadas de sorgo e milheto, mineralização de nutrientes e seus efeitos no solo e na cultura do milho em plantio direto. Lavras, Universidade Federal de Lavras, 2001. 90p. (Tese em Mestrado)

MUZILLI, O. Princípios e perspectivas de expansão. In: Plantio direto no Estado do Paraná. Londrina, IAPAR, 1981. p.1170 .

OLIVEIRA, T.K. Plantas de cobertura em cultivo solteiro e consorciado e seus efeitos no feijoeiro e no solo em plantio direto. Lavras, Universidade Federal de Lavras, 2001. 109 p. (Tese de Mestrado)

REICOSKY, D.C. \& FORCELLA, F. Cover crop and soil quality interactions in agroecosystems. J. Soil Water Conserv., 53:224-229, 1998

REZENDE, C.P.; CANTARUTTI, R.B.; BRAGA, J.M.; GOMIDE, J.A.; PEREIRA, J.M.; FERREIRA, E.; TARRÉ, R.; MACEDO, R.; ALVES, B.J.R.; URQUIAGA, S.; CADISCH, G.; GILLER, K.E. \& BODDEY, R.M. Litter deposition and disappearance in Brachiaria pastures in the Atlantic forest region of the South of Bahia, Brazil. Nutr. Cycling Agroecosyst., 54:99-112, 1999.

SANTOS, P.F. \& WHILFORD,W.G. The effects of microarthropods on litter decomposition in a chihuazhuan ecosystem. Ecology, 62:654-669, 1981.

SCHUNKE, R.M. Qualidade, decomposição e liberação de nutrientes da liteira de quatro cultivares de Panicum maximun. Seropédica, Universidade Federal Rural do Rio de Janeiro, 1998. 88p. (Tese de Doutorado)

SILVA, T.O. \& MENEZES, R.S.C. Adubação orgânica da batata com esterco e, ou, crotalária juncea. II - Disponibilidade de N, P e K no solo ao longo do ciclo de cultivo. R. Bras. Ci. Solo, 31:51-61, 2007.

SORATO, R.P. \& CRUSCIOL, C.A.C. Cátions hidrossolúveis na parte aérea de culturas anuais mediante aplicação de calcário e gesso na superfície. R. Bras. Ci. Solo, 31:81-90, 2007.

SOUZA, W.J.O. \& MELO, W.J. Teores de nitrogênio no solo e nas frações da matéria orgânica sobre diferentes sistemas de produção de milho. R. Bras. Ci. Solo, 24:885-896, 2000.

TAIZ, L. \& ZEIGER, E. Plant physiology. Redwood City, Benjamin/Cummings Publishing Company, 1991. 565p.

TEDESCO, M.J.; VOLKWEISS, S.J. \& BOHNEN, H. Análise de solo, plantas e outros materiais. Porto Alegre, Universidade Federal do Rio Grande do Sul, 1985. 188p. (Boletim Técnico de Solos, 5)

THOMAS, R.J. \& ASAKAWA, N.M. Decomposition of leaf litter from tropical forage grasses and legumes. Soil Biol. Biochem., 25:1351-1361, 1993.

TORRES, J.L.R. Estudo das plantas de cobertura na rotação milho-soja em sistema de plantio direto no Cerrado, na região de Uberaba - MG. Jaboticabal, Universidade Estadual Paulista, 2003. 108p. (Tese de Doutorado) 
TORRES, J.L.R.; PEREIRA, M.G.; ANDRIOLI, I.; POLIDORO, J.C. \& FABIAN, A.J. Decomposição e liberação de nitrogênio de resíduos culturais de plantas de cobertura em um solo de Cerrado. R. Bras. Ci. Solo, 29:609-618, 2005 .
TORRES, J.L.R.; PEREIRA, M.G.; FABIAN, A.J. \& PAULA, J.C. Efeito da temperatura do ar e precipitação pluviométrica na decomposição de plantas de cobertura no Cerrado. In: CONGRESSO BRASILEIRO DA CIÊNCIA DO SOLO, 31., Gramado, 2007. Anais... Gramado, SBCS/UFRGS, 2007. CD-ROM. 